\title{
Improvement of Restricted Interests and Adaptive Behavior in People with Autism Spectrum Disorders
}

\author{
Manuel Ojea Rúa \\ University of Vigo \\ Pontevedra, Spain
}

\begin{abstract}
Autism Spectrum Disorders (ASD) is characterized by deficits in reciprocal social behavior, communication, and behavioral flexibility that might be explained in terms of reduced perceptual similarity and that reduced perceptual similarity could also account for the difficulties that people with ASD have to adjust their behavior in the context. This study is a pre-post design of three groups $(N=15)$, which was carried out for 6 months, with the aim of comparing the effects of three different programs application to improve the the behavior adaptation to the environment of students with ASD. Results were analyzed using comparative standard statistical techniques. This analysis revealed that individuals with ASD found the highest post-intervention scores on adaptive behavior into Integrated Sensory Program group, in relation the another two study programs: A-B Behavior Program and Curricular Program.
\end{abstract}

Keywords: Autism Spectrum Disorder, Restricted Interests, Behavior, Sensory Development.

\section{Introduction}

Individuals with Autism Spectrum Disorder (ASD) are defined by the International Classification of Mental Disorders (American Psychiatric Association, 2013) as a continuum of basic needs in restrictive, repetitive and limited behaviors than influence global and adaptive behavior. Frith (2004), Happe (1997), Happe \& Frith (2006) and Plaisted (2001) also show this set of diagnostic symptoms is related to particular perceptual processing of information, characterized by high selection of stimuli in evaluating experiences. Evaluation does not only analyze contextual processes but, furthermore, response and functional behavior in environment are also influenced, thus limiting behavior opportunities to expanding preferences and activities in the social context.

One subtype of restricted and repetitive behavior is restricted interest in actions, which describe how people carry out activities in interaction with the environment.

People with ASD might engage with a narrow range of actions or an exclusive behavioral activity in order to develop their social interaction, and, as a result, this deficit might lead to limited sources of stimulation achieving social, communication and educational goals. Moreover, interrupting the engagement of an individual with restricted interests might result in severe limitation of general behavior (Boyd et al., 2007).

Such limitations involve deficits in restricted and repetitive behavior (Stocco, Thompson \& Rodríguez, 2011) with a high risk of social exclusion in social interaction with peers (Rossi, Vladescu, Reeve \& Gross, 2017). Adjustment of responses to the partner's requirements may be limited even when behavioral kinds are learned (Elliott \& Dillenburger, 2016; Vershuur, Huskens, Verhoeven \& Didden, 2017).

For this reason, Ojea (2017) shows that diagnosis cannot be an isolated process limited to simply observable behavior, but rather must form part of the functional interrelation of the sensory system, in which neuropsychological processes form an integral part of an overall process, with this being basic in designing specific behavioral development programs.

In consequence, learning programs should not be limited to teaching isolated behaviors and improving disconnected goals, but rather restricted behavior must develop from individuals' behavioral repertoires based on reinforcing emotional interactions, which are closely linked to other cognitive factors, in order to ensure this behavior is as flexible as possible and promotes positive development of general behavior. 
This requires all interrelated sensorial processes to be simultaneously activated throughout learning, which also forms part of cognitive development, including emotional and motivational dimensions as basic elements to increase behavior skills by improving flexibility and behavior interests.

Garris, Ahlers \& Driskell (2002) and Grandin (1996) concluded that sensory integration refers to organizing and integrating different feelings transmitted by diverse components in cognitive systems to work together, thus allowing interaction with the context.

This training includes providing whole psycho-neurological elements that stimulate the vestibular system, proprioception and sense of touch, with motor training being most common in sensory integration training. Sensory integration therapy, which can develop basic motor ability through activity and actions should therefore be carried out.

Li, Lou, Tsai \& Shih (2012) explore the effects of applying game-based learning to webcam motion sensor games for sensory integration training for students. Conclusions showed that webcam motion sensor games can enhance interest in learning among autistic students.

Morrison, Roscoe \& Atwell (2011) conducted research to identify leisure and exercise associated with high levels of engagement and a low level of behavior interests to reduce problematic behavior through three component multiple-schedule sequences: 1) an antecedent exercise test sequence; 2) a non-contingent leisure-item control sequence; and 3) a social interaction control sequence. Problem behavior decreased during post-intervention as a consequence of the program.

Todd, Reid \& Butler- Kisber (2010) investigated the effect of a self-regulation instructional strategy on sustained cycling, which included self-monitoring, goal-setting and self-reinforcement. Results suggest that self-regulation interventions can improve behavior.

Lee \& Vargo (2017) used interrelated physical activity to improve development of social skills through movement. Also, López, Moreno- Rodríguez, Alcover, Garrote \& Sánchez (2017) provided arguments for a motor teaching methodology to improve behavioral and social development.

Furthermore, a range of studies point to the use of music, psycho-motor skills or video to facilitate integrated sensory development and improve global behavior (Mahoney \& Solomon, 2016; Kossyvaki, Jones \& Guldberg, 2016; Preece et al., 2017).

Well, the main aim of this research study is therefore to compare the effects of three different programs applied to improve the interests and global behavior of students with ASD.

Restricted behavior-based development was based on three programs applied to three participant groups:

I) Integrated Sensory Program:

The intervention program was structured using three components, all well-sequenced during behavior learning:

1) Analytical understanding of objective-behavior (video-modeling).

2) Relationship of emotions and observed behavior (communication apps).

3) Representation-expression of behavior and related emotions (role-playing psycho-motor activity).

This program was applied to experimental group (1) participants of the Provincial Autism Association from different schools in the area.

II) A-B Behavior Program:

This program was based on standard behavior modification A-B (stimulus-behavior (R) reinforcement), with the following design: positive- behavior= positive- reinforcement/ disruptive- behavior= ignore behavior) (Bandura, Ross \& Ross, 1963; Lovaas, 1987), which was applied to the experimental (2) group of participants at a mainstream secondary education school according to the previously designed behaviors.

III) Curricular Program:

Curricular Program was organized around common educational intervention strategies at a mainstream secondary school (constituting the control group) to be used whenever disruptive behavior occurred.

\section{Research Method}

Basic Hypothesis

Applying integrated sensory development in the learning of interests and behaviors improves global behavior of individuals with ASD compared to the other two programs analyzed. 


\section{Design}

The research design is based on an experimental model of pre-tests and post-tests in three groups: I) Integrated Sensory Program group, related to an experimental program that integrates the diverse sensory components of the cognitive system; II) A-B Behavior Program group, formed by applying a standard behavior modification program; and III) Curricular Program, referring to mainstream educational development.

\section{Participants}

A total of 15 children with a specific diagnosis of level 1 ASD (American Psychiatric Association, 2013), made up of 13 boys and 2 girls aged 12-14 years, was distributed in three experimental groups corresponding to three programs: 1) integrated program group $(\mathrm{N}=5)$; 2) A-B behavior program group $(\mathrm{N}=5)$; 3) curricular program group $(\mathrm{N}=5)$.

\section{Variables}

Children's social adjustment development has been studied by analyzing two variables included in the Autism Diagnostic Interview- Revised (ADI-R) (Le Couteur, Lord \& Rutter (2006): 1) Interests variable (pre-post), which measures interest and behavior level (subtest dimension ADI-R: Interests and Behaviors); and 2) Global variable (pre-post), in order to analyze general behavior (subtest dimension ADI-R: General Behavior). Both variables were related to Group variable (group type).

\section{Procedure}

After obtaining informed consent from the parents, the research was carried out over the course of 6 months. It was organized in two phases.

Phase 1 included the pre-test analysis in the three groups and the program design for the Integrated Sensory Program group and the A-B Behavior Program group. The Integrated Sensory Program was applied through weekly sessions, with each session lasting 60 minutes. The A-B Behavior Program was carried out based on the analysis of positive-disruptive behaviors and potential reinforcements were designed ad hoc for each student. Curricular group participants did not follow a structured program, since the intervention developed in accordance with the disruptive behaviors exhibited.

Phase 2 post-test analysis was carried out in the three groups after 6 months, in order to evaluate the effectiveness of the programs and compare the intergroup data of the interventions.

\section{Data analysis}

Data was analyzed using the following analysis tests: 1) descriptive Analysis of the study; 2) analysis of Multivariate Tests Within-Subjects Effects; 3) pairwise comparisons for the three groups; and 4) comparative measurement for $k$ independent samples of Kruskal Wallis Test.

\section{Results}

Preliminary statistical analysis was indicated in Table 1. Students improved on the treatment objectives in all groups, so from pre- test (Interests $=\mu: 3.20 ; \sigma=.77$ and Golobal $\left._{l}=\mu: 3.06 ; \sigma: .70\right)$ compared to post-test (Interest $s_{2}=\mu: 5.06 ; \sigma: 1.16$ and Global $_{2}=\mu: 4.86 ; \sigma: 1.30$ ).

\section{Table 1: Descriptive statistics.}

\begin{tabular}{lllllll}
\hline & $\mathrm{N}$ & Minimum & Maximum & Sum & Mean & Std. Deviation \\
\hline Interests1 & 15 & 2.00 & 4.00 & 48.00 & 3.20 & .77 \\
Interests2 & 15 & 3.00 & 7.00 & 76.00 & 5.06 & 1.16 \\
Global1 & 15 & 2.00 & 4.00 & 46.00 & 3.06 & .70 \\
Global2 & 15 & 2.00 & 7.00 & 73.00 & 4.86 & 1.30 \\
Valid N & 15 & & & & & \\
\hline
\end{tabular}

Tests of Between- Subjects Effects was used to compare the results of the Factor $_{1}$ variable (interactive scores of the four variables Interests ${ }_{1-2}$ and Global $_{1-2}$ ) in relation for the three study's groups (see Table 2). 
Table 2: Tests of Between-Subjects Effects.

Measure: MEASURE_1

\begin{tabular}{lllllll}
\hline Source & & Type III Sum of Squares & Df & Mean Square & F & Sig. \\
\hline Factor1 & Assumed Sphericity & 44.28 & 3 & 14.76 & 85.84 & .00 \\
& Greenhouse- Geisser & 44.28 & 1.91 & 23.09 & 85.84 & .00 \\
& Huynh- Feldt & 44.28 & 2.94 & 15.03 & 85.84 & .00 \\
Factor1 * Group & Lower- bound & 44.28 & 1.00 & 44.28 & 85.84 & .00 \\
& Assumed Sphericity & 12.50 & 6 & 2.08 & 12.12 & .00 \\
& Greenhouse-Geisser & 12.50 & 3.83 & 3.26 & 12.12 & .00 \\
& Huynh- Feldt & 12.50 & 5.89 & 2.12 & 12.12 & .00 \\
Error (Factor1) & Lower-bound & 12.50 & 2.00 & 6.25 & 12.12 & .00 \\
& Assumed Sphericity & 5.67 & 33 & .17 & & \\
& Greenhouse-Geisser & 5.67 & 21.09 & .26 & & \\
& Huynh- Feldt & 5.67 & 32.41 & .17 & & \\
& Lower- bound & 5.67 & 11.00 & .51 & & \\
\hline
\end{tabular}

According to this analysis, the following essential results were analyzed:

1) Concerning pointing the increase in the Factor $_{1}$ scores, the results find the significant improvement in intercept source (Between- Subjects Effects= Sig: .00).

2) Multivariate Comparative Test showing a significant interaction the Factor ${ }_{l}$ with Group variable (Sig: .00), which means that changes in Factor $_{1}$ are related to the group type. Sex variable doesn't influence the scores in the Factor $_{1}$ (Assumed Sphericity= Sig: .72).

However, no significant relationships found between the three groups as indicated by the critical level of the Pairwise Comparisons (see Table 3).

Table 3: Pairwise Comparisons.

Measure: MEASURE_1

\begin{tabular}{|c|c|c|c|c|c|c|}
\hline \multirow[t]{2}{*}{ (I) Group } & \multirow[t]{2}{*}{ (J) Group } & \multirow[t]{2}{*}{$\begin{array}{l}\text { Mean } \\
\text { Difference } \\
(\mathrm{I}-\mathrm{J})\end{array}$} & \multirow[t]{2}{*}{$\begin{array}{l}\text { Std. } \\
\text { Error }\end{array}$} & \multirow[t]{2}{*}{ Sig.(a) } & \multicolumn{2}{|c|}{$\begin{array}{l}\text { 95\% Confidence Interval for } \\
\text { Difference(a) }\end{array}$} \\
\hline & & & & & Lowe Bound & Upper Bound \\
\hline \multirow{2}{*}{$\begin{array}{l}\text { Integrated Sensory } \\
\text { Program }\end{array}$} & A-B Behavior Program & .53 & .54 & .34 & -.65 & 1.73 \\
\hline & Curricular program & .95 & .52 & .09 & -.20 & 2.10 \\
\hline \multirow[t]{2}{*}{$\begin{array}{l}\text { A-B Behavior } \\
\text { Program }\end{array}$} & $\begin{array}{l}\text { Integrated Sensory } \\
\text { Program }\end{array}$ & -.53 & .54 & .34 & -1.73 & .65 \\
\hline & Curricular program & .41 & .54 & .46 & -.78 & 1.60 \\
\hline \multirow[t]{2}{*}{ Curricular Program } & $\begin{array}{l}\text { Integrated Sensory } \\
\text { Program }\end{array}$ & -.95 & .52 & .09 & -2.10 & .20 \\
\hline & A-B Behavior Program & -.41 & .54 & .46 & -1.60 & .78 \\
\hline
\end{tabular}

Based on estimated marginal means.

a) Adjustment for multiple comparisons: Least significant difference (equivalent to no adjustments).

Integrated Sensory Program group scores didn't were found relationships with A-B behavior program group (Sig: .54) nor with the curricular program group (Sig: .09). Likewise, A-B Behavior Program group didn't significant relationships with Curricular Program group (Sig: .46).

Kruskall Wallis Test was conducted to compare the significances of scores in the evolution of the two variables: Interests and Global into the pre-intervention and post- intervention (see Table 4). 
Table 4: Test statistics (ab).

\begin{tabular}{lllll}
\hline & Interests1 & Interests2 & Global1 & Global2 \\
\hline Chi-Square & .00 & 4.12 & .29 & 9.49 \\
Df & 2 & 2 & 2 & 2 \\
Asymp. Sig. & 1.00 & .12 & .86 & .00 \\
\hline
\end{tabular}

a) Kruskal Wallis Test.

b) Grouping variable: Group.

Results no significant differences were found in children's development in the three compared groups over the pre- intervention (pre-tests), but there're significant differences into post- intervention in Global2 variable. This study revealed, then, that after 6 months of intervention, children's development with ASD showed improvement on the Integrated Sensory Program in relation to the other two groups: A-B Behavior Program group and Curricular Program group.

Likewise, Graph 1 could be observed the improvement achieved in the three study groups.

\section{Graph 1: Assessment results of the Factor1 (Interests: 1-2, Global: 3-4) to Group variable.}

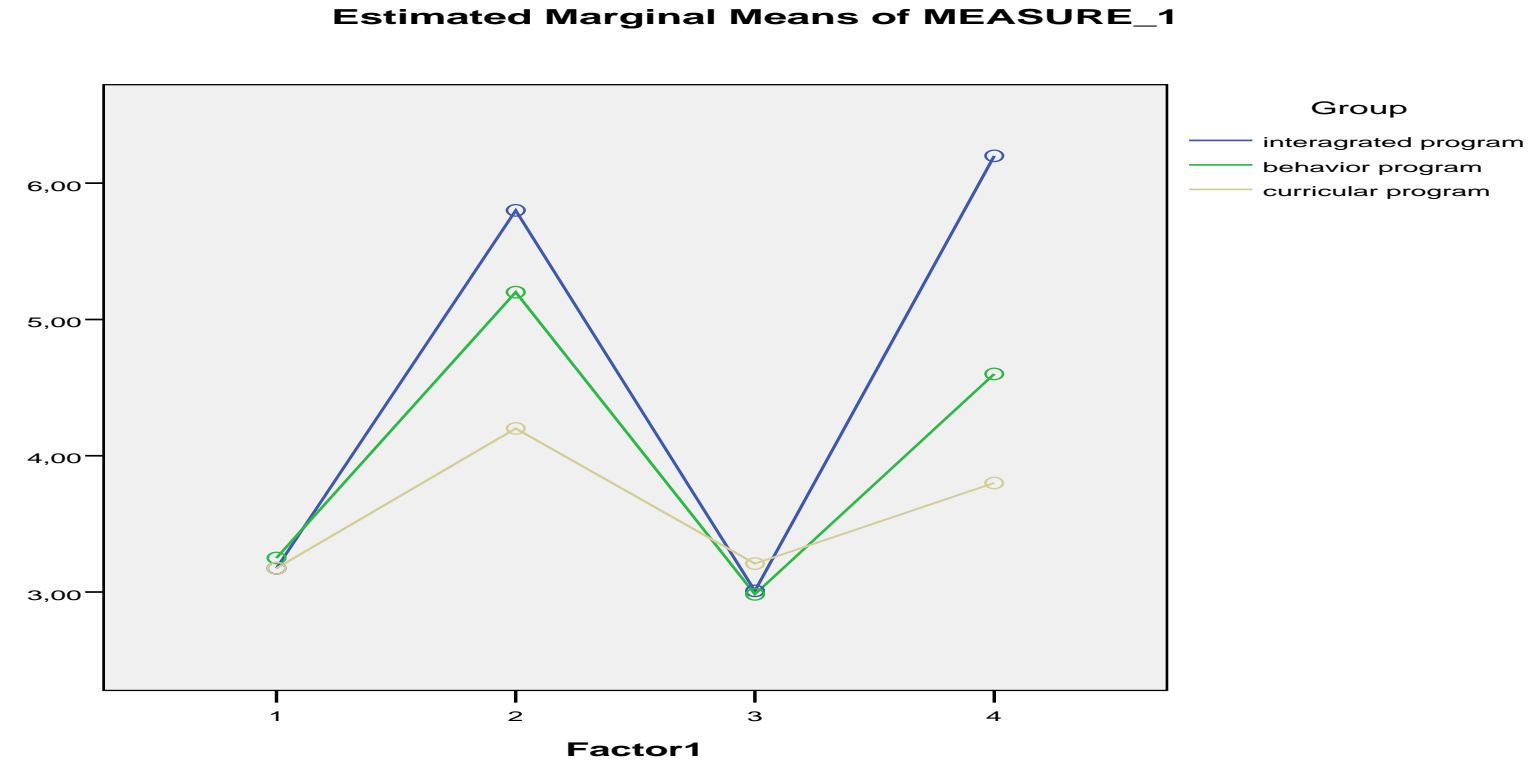

Indeed, data indicate the development in Global2 (score 4) of the Integrated Sensory Program group was highlighted followed by the A-B Behavior Program group and, finally, Curricular Program.

\section{Discussion}

All participants in the study improved in restrictive and repetitive behavior and, consequently, in global behavior tasks; however, the group made up of participants of the Integrated Sensory Program significantly improved the highest scores in Global 2 : general behavior, followed by the A-B Behavior Program group, and, finally, the lowest scores were found in the Curricular Program participants.

This basic hypothesis was therefore corroborated since the interaction of emotional-motivational and behavioral dimensions of the Integrated Sensory Program facilitated the flexibility of restricted behavior and enhanced overall behavior positive in the environment for children with ASD.

In general, the findings of the study should show that sensory integration had a significant effect on learner emotion and motivation in behavior instruction as a result of applying interrelated multiple psycho-neurological dimensions over learning (Mizelle, Hart \& Carr, 1993; Small \& Gluck, 1994). 
Indeed, the limitations in recognizing emotional expressions are directly correlated with a deficit in empathic interaction, which is also characteristic of individuals with ASD and their interactive behavior in the context, as there is an accumulation of evidence illustrating an association between affect recognition and social functioning. The empathic process is developed through two basic components: an affective component and a cognitive component, both of which interact to integrate understanding about the behavior of others and, therefore, to behave in a way in keeping with the environment (Harms, Martín \& Wallace, 2010; Hooker \& Park, 2002; Jones, Gilbert, Burnett \& Viding, 2010; Smith \& McKie, 2008).

However, the interaction of emotional and cognitive components will be a process which students actively learn. The methodology strategies will therefore have two main characteristics: 1) a constructivist learning of the objective concept (behavior); 2) emotion-concept interaction through the interactive movement of the motor system (dynamic motor); and 3) multiple channel interaction of the sensory and vestibular systems (sensory integration).

In synthesis, there is an increase in behavior interests around the objective behavior, greater flexibility and a reduction of stereotyped and repetitive behavior, meaning behavior itself is improved. Lloyd, McDonalds \& Lord (2013), Staples \& Reid (2010) proved that motor skills in people with ASD help achieve successful communicative ability, meaning children with excellent motor skills will also show good social and communication skills, as well as flexibility and adaptive behavior during their social participation. It should be noted that the benefits are higher when obtained in a familiar social context in which the programs applied with children with ASD constitute an active process of interaction and participation with other children, and achieve a relevant social positive effect on general behavior.

\section{Conclusions}

This research study found that intervention improved children's global behavior, with a higher improvement being observed in the Global $_{2}$ post- intervention score of the Integrated Sensory Program group, compared to the other two study programs.

This study therefore adds to existing research into the effects of the interrelated programs, and is necessary for a complete understanding of development and generalization of behavior (Hanley, Iwata \& McCord, 2003; Sloman et al., 2005).

In summary, it's therefore necessary to facilitate a constructive movement, defined as a related interactiveaffective approach, in order to facilitate improvement and intersubjective development of both one's own interests and feelings and also those of others, through a multimodal exchange process:

1. Understanding specific behavior (cognitive teaching through video-modeling role-playing).

2. Sensory integration of behavior effects (emotional-motivational and motor components).

3. Functional application of behavior (familiar and social context).

4. Behavior generalization (development of learned behavior in changed context based on acquired interests).

\section{Study limitations}

The results of this study should be interpreted with caution due the small sample involved, as common in research into this disorder, especially ASD; however, this does not mean that its conclusions cannot be effective or their outcomes applied in other programs to improve the future of programs designed for people with ASD.

\section{References}

American Psychiatric Association (2013). Diagnostic and statistical manual of mental disorders DSM- $5^{\circledR}$ (5th ed.). Arlington, Va: American Psychiatric Association.

In https://dsm.psychiat ryonline.org/doi/book/10.1176/a ppi.books.9780890425596.

Bandura, A., Ross, D. \& Ross, S. (1963). Imitation of film-mediated aggressive models. Journal of Abnormal and Social Psychology, 66, 3-11. Doi:10.1037/h0048687

Boyd, B. A., Conroy, M. A., Mancil, G. R., Nakao, T. \& Alter, P. J. (2007). Effects of circumscribed interests on the social behaviors of children with autism spectrum disorders. Journal of Autism and Developmental Disorders, 37, 1550-1561.In https://www.ncbi.nlm.nih.gov/pubmed/17146704 
Elliott, C. \& Dillenburger, K. (2016). The effect of choice on motivation for young children on the Autism Spectrum during discrete trial teaching. Journal of Research in Special Educational Needs, 16(3), 187198. In http://dx.doi.org/10.1111/1471-3802.12073

Frith, U. (2004). Autism: Explaining the enigma. Madrid: Alianza Editorial. In https://www.alianzaeditorial.es/libro.php?id=734229\&id_col=100508\&id_subcol=100518

Garris, R., Ahlers, R. \& Driskell, J. E. (2002). Games, motivation, and learning: A research and practice model. Simulation \& Gaming, 33 (4), 441-467. In http://journals.sagepub.com/doi/pdf/10.1177/1046878102238607

Grandin, T. (1996). Brief Report: Response to National Institutes of Health Report. Journal of Autism and Developmental Disorders, 26, 185-187. In https://pdfs.semanticscholar.org/4766/d1c40f43b475dd3dba8bb242987edb5ac3df.pdf

Hanley, G. P., Iwata, B. A. \& McCord, B. E. (2003). Functional analysis of problem behavior: A review. Journal of Applied Behavior Analysis, 36, 147-185. In https://www.ncbi.nlm.nih.gov/pmc/articles/PMC12 84431/pdf/12858983.pdf

Happe, F. \& Frith, U. (2006). The weak coherence account: detail-focused cognitive style in autism spectrum disorders. Journal of Autism and Developmental Disorders, 36(1), 5-25. In https://link.springer.com/article/10. 1007\%2Fs 10803-005-0039-0

Happe, F. (1997). Central coherence and theory of mind in autism: reading homographs in context. British Journal of Developmental Psychology, 15, 1-12.

Harms, M., Martin, A. \& Wallace, G. (2010). Facial Emotion Recognition in Autism Spectrum Disorders: A Review of Behavioral and Neuroimaging Studies. Neuropsychology Review, 20, 290-322. Doi: 10.1007/s11065-010-9138-6

Hooker, C. \& Park, S. (2002). Emotion processing and its relationship to social functioning in schizophrenia patients. Psychiatry Research, 112, 41-50. In http://www.psy.vanderbilt.edu/faculty/sohee/Publications/Hooker\&Park.2 002.pdf

Jones, A., Happe, F., Gilbert, F., Burnett, S. \& Viding, E. (5010). Feeling, caring, knowing: different types of empathy deficit in boys with psychopathic tendencies and autism spectrum disorder. Journal of Child Psychology and Psychiatry,51(11), 1188-1197. Doi: 10.1111/j.1469-7610.2010.02280.x

Kossyvaki, L., Jones, G. \& Guldbert, K. (2016). Training teaching staff to facilitate spontaneous communication in children with autism: Adult Interactive Style Intervention (AISI). Journal of Research in Special Educational Needs, 16(3), 156-168. In http://dx.doi.org/10.1111/1471-3802.12068

Le Couteur, A., Lord, C. \& Rutter, M. (2006). ADI- R Autism Diagnostic Interview Revised. Madrid: TEA Ed. In https://web.teaediciones.com/adi-r-entrevista-para-el-diagnostico-del-autismo---revisada.aspx

Lee, J. \& Vargo, K. K. (2017). Physical activity into socialization: A movement-based social skills program for children with Autism Spectrum Disorder. Journal of Physical Education, Recreation \& Dance, 88(4), 7 13. In http://dx.doi.org/10.1080/07303084.2016.1270788

Li, K. H., Lou, Sh. J., Tsai, H. Y. \& Dhih, R. Ch. (2012). The effects of applying game- based learning to webcam motion sensor games for autistic student's sensory integration training. TOJET: The Turkish Online Journal of Educational Technology, 11(4), 451-459. In http://seab.envmed.rochester.edu/jaba/index.html

Lloyd, M., McDonald, M. \& Lord, C. (2013). Motor skills of toddlers with autism spectrum disorders. Autism: The International Journal of Research and Practice, 17(2), 133-146. In https://doi.org/10.1177/136236131140223

López, J. M., Moreno- Rodríguez, R., Alcover, C. M., Garrote, I. \& Sánchez, S. (2017). Effects of a program of sport schools on development of social and psychomotor skills of people with Autistic Spectrum Disorders: A Pilot Project. Journal of Education and Training Studies, 5(8), 167-177. In http://jets.redfame.com

Lovaas, O. I. (1987). Behavioral treatment and normal educational and intellectual functioning in young autistic children. Journal of Consulting and Clinical Psychology, 55, 3-9. Doi:10.1037/0022-006X.55.1.3

Mahoney, G. \& Solomon, R. (2016). Mechanism of developmental change in the PLAY Project Home Consultation Program: Evidence from a randomized control trial. Journal of Autism and Developmental Disorders, 46(5), 1860-1871. In http://dx.doi.org/10.1007/s10803-016-2720-x 
Mizelle, N. B., Hart, L. E. \& Carr, M. (1993). Middle grade students' motivational processes and use of strategies with expository text. Annual Meeting of the American Educational Research Association, Atlanta, GA, April 12-16, 1993.

Morrison, H., Roscoe, E. M. \& Atwel, A. (2011). An evaluation of antecedent exercise on behavior maintained by automatic reinforcement using a three- component multiple schedule. Journal of Applied Behavior Analysis, 44(3), 523-541. In http://www.eric.ed.gov/contentdelivery/servlet/ERICServlet?accno=EJ941691

Ojea, M. (2017). Autism Spectrum Disorder: Processing of perceptual- cognitive information through the semantic networks learning. https://www.edicionespiramide.es/libro.php?id=5151386

Plaisted, K. (2001). Reduced generalization in autism: An alternative to weak central coherence. In J. A. Burack, T. Charman, N. Yirmiya \& P. R. Zelazo (Eds.), The development of autism: Perspectives from theory and research (pp. 149-169). Hillsdale, NJ: Erlbaum.

Preece, D., Symeou, L., Stošic, J., Troshanska, J., Mavrou, K., Theodorou, E. \& Frey, J. (2017). Accessing parental perspectives to inform the development of parent training in autism in South-Eastern Europe. European Journal of Special Needs Education, 32(2), 252-269.

In http://dx.doi.org/10.1080/08856257.2016.1223399

Ross, M. R., Vladescu, J. C., Reeve, K. F. \& Gross, A. C. (2017). Teaching safety responding to children with Autism Spectrum Disorder. Education and Treatment of Children, 40(2), 187-208.

In http://www.wvupress.com/index.php

Sloman, K. N., Vollmer, T. R., Cotnoir, N. M., Borrero, C. S. W., Borrero, J. C., Samaha, A. L. \& Claire, C. S. P. (2005). Descriptive analyses of caregiver reprimands. Journal of Applied Behavior Analysis, 38, 373-383. In https://www.ncbi.nlm.nih.gov/pmc/articles/PMC1226170/

Small, R. V., \& Gluck, M. (1994). The relationship of motivational conditions to effective instructional. Educational Technology, 36(8), 33-40. In https://eric.ed.gov/?id=EJ491539

Smith, E. R. \& Mackie, D. M. (2008). Intergroup emotions. Handbook of emotions, 3, 428-439. In https://books.google.es/books?hl=es\&lr=\&id=uIQQskejGwUC\&oi=fnd\&pg=PA428\&dq=Smith,+E.+R., +\%26+Mackie,+D.+M.+(2008).+Intergroup+emotions.+Handbook+of+emotions, $+3,+428-$ 439.\&ots=3PUhPMilCe\&sig=ni6KpCB5baoqWtEetqoJJr3cQ2g\#v=onepage \&q\&f=false

Staples, K. L. \& Reid, G. (2010). Fundamental movement skills and autism spectrum disorders. Journal of Autism and Developmental Disorders, 40(2), 209-17. In https://doi.org/10.1007/s10803-009-0854-9

Stocco, C. S., Thompson, R. H. \& Rodríguez, N. M. (2011). Restricted interests and teacher presentation of items. Journal of Applied Behavior Analysis, 44(3), 499-512.

In http://www.eric.ed.gov/con tentdelivery/servlet/E RICServlet?accno=EJ941688

Todd, T., Reid, G. \& Butler- Kisber, L. (2010). Cycling for students with ASD: Self-regulation promotes sustained physical activity. Adapted Physical Activity Quarterly, 27(3), 226-241.

Inhttp://journals.humankinetics.com/apaq-current-

issue/APAQVolume27Issue3July/CyclingforStudentsWithADSelfRegulationPromotesSustainedPhysical Activity

Vershuur, R., Huskens, B., Verhoeven, L. \& Didden, R. (2017). Increasing opportunities for question-asking in school-aged children with Autism Spectrum Disorder: effectiveness of staff training in pivotal response treatment. Journal of Autism and Developmental Disorders, 47(2), 490-505.

In http://dx.doi.org/10.1007/s10803-016-2966-3 